NBER WORRING PAPER SERIES

PREGNANCY RESOLUTION AS AN INDICATOR OF WANTEDNESS AND ITS IMPACT ON THE INITIATION OF EARLY PRENATAL CARE

Theodore J. Joyce

Michael Grossman

Working Paper No. 2827

\author{
NATIONAL BUREAU OF ECONOMIC RESEARCH \\ 1050 Massachusetts Avenue \\ Cambridge, MA 02138 \\ January 1989
}

Research for this paper was supported by Grant Number 1 Rol HD24154 from the National Institute of Child Health and Human Development to the National Bureau of Economic Research. We are indebted to the following people for supplying us with data without which this research could not have been undertaken: Jean Lee and Louise Berenson of the Division of Biostatistics, New York City Department of Health; Stanley Henshaw of the Alan Guttmacher Institute; and Marc Jacobs and Jonah Otelsberg of he City University of New York Data Service. We are also indebted to Victor Fuchs, Hope Corman, and Cordelia Reimers for helpful comments and suggestions. Finally, we wish to thank Frank Chaloupka, Pamela Mobilia, and Naci Mocan for research assistance. This paper has not undergone the review accorded official NBER publications; in particular, it has not been submitted for approval by the Board of Directors. This paper is part of NBER's research program in Health Economics. Any opinions expressed are those of the authors and not those of the NBER, the NICHD, or the Kaiser Foundation. 
NBER Working Paper \#2827

January 1989

\section{PREGNANCY RESOLUTION AS AN INDICATOR OF WANTEDNESS AND ITS IMPACT ON THE INITIATION OF EARLY PRENATAL CARE}

\section{ABSTRACT}

The study examines the impact of the wantedness of a pregnancy on the demand for early prenatal care. Past attempts to address this question have depended on the self-assessments of women as to the wantedness of their pregnancy and birth. Our approach can be described as a form of revealed preference in which only those pregnancies that are voluntarily terminated by induced abortion are considered to be unwanted. Using a cohort of pregnant women in New York City, we estimate a prenatal care demand function in which we control for the probability of giving birth, given a woman is pregnant. We interpret this control as a measure of wantedness. The results indicate that if the black and Hispanic women who aborted, had instead given birth, they would have delayed the initiation of prenatal care, on average, over three-quarters of a month Jonger than the mean number of months of delay that were actually observed for the women who gave birth. By allowing women to terminate an unwanted pregnancy, induced abortion increases the average utilization of prenata? care among black and Hispanic women relative to what would have been observed if the women who aborted had instead given birth.

Theodore Joyce

Department of Health Care Administration

Baruch College

City University of New York

17 Lexington Avenue New York, NY 10010

\section{Michael Grossman \\ Department of Economics \\ City University of New York Graduate School}

33 W. 42nd Street

New York, NY 10036

\footnotetext{
National Bureau of Economic Research

269 Mercer Street, 8th Floor

New York, NY 10003
} 


\section{Introduction}

Two recent and comprehensive reports on infant health in the United States both recommended that efforts be directed at reducing the number of unintended or unwanted pregnancies. (Institute of Medicine 1985; United States Department of Health and Human Services 1986.) The recommendation was based on the proposed link between pregnancy planning, improved prenatal behavior, and favorable birth outcomes. Specifically, women who choose to become pregnant are apt to be better prepared emotionally and financially for the demands of pregnancy and childbearing. Thus, they may be more likely to avoid smoking, to seek out prenatal care earlier, and in general to have a more heightened concern for the impact of their behavior on the health of the fetus than women whose pregnancies were unwanted or unintended.

As plausible as the recommendation appears, the evidence supporting it is scarce. A number of ecological analyses have documented a relationship between the use of family planning clinics and lower rates of neonatal mortality (Grossman and Jacobowitz 1981; Joyce 1987a). The availability and use of abortion services have also been associated with improvements in area-wide birth outcomes (Corman and Grossman 1985; Joyce 1987b). The authors argue that the utilization of contraception and abortion should be inversely related to the incidence of unwanted pregnancies and births and positively related to the increased use of prenatal care and other healthy behaviors.

At the individual level, there is some evidence that women who describe their births as wanted begin prenatal care earlier and smoke less during pregnancy (Weller, Eberstein, and Bailey 1987; Marsiglio and Mott forth- 
coming). However, the methodological problems of using self-assessments to measure wantedness are substantial. For instance, the timing of the assessment can affect the response since a woman's attitude towards her pregnancy and birth may be shaped by the experience itself. 1 Social circumstances can also affect a woman's response (Klerman and Jekel 1984). Teenagers and unmarried women may be more inclined to say that their pregnancies are unwanted because of the social stigmas attached to young and out-of-wedlock childbearing. Similarly, married women may feel inhibited about describing their births as unwanted especially if their attitudes differ from those of their husbands. Perhaps the most serious drawback is that most research has focused on women whose pregnancies end in a live birth. This excludes all pregnancies that are terminated by incuced abortion.

In this study we investigate the impact of pregnancy resolution on the demand for prenatal care by treating women who give birth as a selfselected sample from the population of pregnant women. It is our hypothesis that pregnant women who choose to give birth differ in unobserved ways from similar women who voluntarily terminate their pregnancies. A distinguishing characteristic is the wantedness of the pregnancy.

Our approach can be described as a form of revealed preference in which only those pregnancies that are voluntarily terminated are considered to be unwanted. In statistical terms, we treat women who give birth as a censored sample from the population of pregnant women. Such a framework

1For example, Marsiglio and Mott (forthcoming) point out that after controling for numerous characteristics, women who reported on their pregnancies while pregnant were more likely to have wanted the pregnancy than women who reported after giving birth. Moreover, among the subsample 
allows us to exploit the well-developed econometrics on selectivity bias (Heckman 1979; Maddala 1983). As a result, we estimate a demand function for prenatal care in which we control for the probability of giving birth given a woman is pregnant. We interpret this control as a measure of wantedness.

Our study is based on a cohort of pregnant women who were residents of New York City in 1984. New York City is one of 14 vital registration areas in the United States that submits induced abortion reports on individuals to the National Center for Health Statistics (NCHS). By combining 1984 induced termination records with birth certificates in the same year, we were able to generate a sample of pregnant women all of whom had conceived within a twenty-month period. Another reason for choosing New York City is that the proportion of pregnancies (live births plus induced abortions) that are terminated by induced abortion far exceeds national estimates. 2 Thus, the use of induced abortion to distinguish between wanted and unwanted pregnancies may be most effective in an area such as New York where the widespread availability of abortion services makes it a readily accessible option. Finally, the racial and ethnic composition of the city allows us to analyze black, white and Hispanic women separately. The impact of pregnancy resolution on the demand for prenatal care is likely to differ by race and ethnicity given the marked variation in abortion rates by these various groups.

who reported while pregnant, wantedness was not related to early prenatal care.

${ }^{2}$ Forty-six percent of all pregnancies to New York City residents in 1984 were terminated by induced abortion. The average for the other 12 states that reported induced abortions to the National Center for Health Statistics 


\section{Analytical and Statistical Framework}

Self-selection is a potential problem for researchers whenever the subjects under study have not been randomiy assigned. In the economic literature the problem of self selection has received widespread attention following the seminal work of Heckman (1976, 1979). For example, the wages of individuals who have completed a manpower training program are a biased estimate of the wages individuals with similar characteristics would have earned had they gone through the program, since the individuals enrolled in the training program represent a self-selected sample from the population of all potential trainees. Put differently, those who seek out training are likely to differ in unobserved ways (more ability or more ambition) from those who do not. Thus, the success of the training program at improving the earning power of graduates may be less a function of the training per se, and more related to the unmeasured characteristics associated with the trainees.

The notion of self-selection can be readily applied to prenatal behavior. Contraception and abortion have provided women with the means to control the number and timing of their pregnancies and births. Consequently, women who choose to give birth represent a self-selected sample from the population of pregnant women. It is our hypothes is that pregnant women who choose to give birth differ in unobserved ways from

was 21 percent (Powell-Griner 1987; NCHS 1986). Although New York City has a large minority population, the percent of all pregnancies to white non-Hispanic women that were terminated by induced abortion was 45 percent (see Table $A 1$ in the Appendix). 
similar women who voluntarily terminate their pregnancies. A characteristic that distinguishes those who give birth from those who abort is the wantedness of the pregnancy.

From a statistical standpoint, data on prenatal care can be characterized as a censored sample with an unobserved stochastic threshold. In particular, let $M_{i}$ be the month in a woman's pregnancy in which individual $i$ began prenatal care; let $x_{i 1}$ be a vector of exogenous determinants; and let $I_{i}^{*}$ represent a woman's desire to have a child given that she is pregnant There exists some threshold of "wantedness" above which this woman will choose to carry to term. If the wantedness of the pregnancy is below this threshold, then the woman will terminate the pregnancy. $I_{i}^{*}$ is unobserved, yet we do know which pregnancies were terminated by induced abortion. Thus, we know the women for whom the wantedness of a pregnancy was below this threshold. The model can be written as follows:

$$
\begin{aligned}
M_{i} & =X_{i 1} B_{1}+u_{i 1} \quad \text { iff } I_{i}^{\star}>0 \\
I_{i}^{*} & =X_{i 2} B_{2}+u_{i 2} \\
\text { where } \quad I_{i} & =1 \text { if }{ }_{i 1}>0 \\
I_{i} & =0 \text { otherwise }
\end{aligned}
$$

$I_{j}$ is a dummy variable that equals one if a woman gives birth and zero if she aborts. Heckman's insight was that if selection into the subsample was not random, then the expected value of the error term in equation (1) was conditional on the regressors in equation (2). This virtually insured that the estimates of $B_{1}$ obtained by ordinary least squares would be biased given the correlation among the variables in $x_{1}$ and $x_{2}$. 
Heckman's solution was to treat the problen of selectivity bias as a specification error. Heckman (1979) showed that unbiased estimates of equation (1) could be obtained under the assumption that the joint distribution of $u_{i 1}$ and $u_{i 2}$ was bivariate normal. His procedure was to $f_{i t}$ the equation (2) as a probit equation and to compute the inverse of Mill's ratio $\left(\lambda_{i}\right)$ for each woman who gives birth.

$$
\lambda_{i}=f\left(Q_{i}\right) / F\left(Q_{i}\right)
$$

Here $Q_{i}=X_{i 2} B_{2} / \sigma_{2}$ and $f$ and $F$ are, respectively, the density and distribution functions for a standard normal variable. The inverse Mill's ratio is then inserted as a regressor in equation (1) which after adding the disturbance term $\left(v_{i 1}\right)$ becomes:

$$
M_{i 1}=x_{i 1} B_{1}+\left(\sigma_{12} / \sigma_{2}\right) \lambda_{i}+v_{i 1}
$$

The coefficient on $\lambda_{i}$ in equation (4) estimates $\sigma_{12}$ up to a positive scale factor $\left(1 / \sigma_{2}\right)$. The sign of the coefficient on lambda depends on $\sigma_{12}$, which is the covariance between the disturbance terms in equations (1) and (2). Following Trost (1981), we believe that $\sigma_{12}$ has a particularly useful interpretation given the context of our model. For instance, if $M_{i 1}$ is the number of months a woman delays before initiating prenatal care, then women whose pregnancies are more wanted, all else equal, should delay the initiation of prenatal care less than women whose pregnancies are less wanted. Thus, a negative coefficient on lambda, $\left(\sigma_{12}<0\right)$ implies that, on average, women with a greater than expected probability of not aborting (i.e., $u_{i 2}>$ 0 ). have a less than expected delay in the initiation of prenatal care 
$\left(u_{i 1}<0\right) \cdot{ }^{3}$ In short, a negative and statistically significant coefficient on lambda, is consistent with the interpretation that pregnancies that are more wanted, delay the initiation of prenatal care less.

Although we have argued that the wantedness of a pregnancy distinguishes women who abort from women who give birth, clearly caution is in order when giving names to unmeasured variables. For example, a model in which the cost of contraception is the underlying unobservable would generate the same predictions as a model based on wantedness. Specifically, a decrease in contraceptive costs, all else constant, diminishes the probability of an unintended pregnancy, and decreases the likelihood of aborting. This lowers optimal family size and raises the investments per child (Willis 1973). On the other hand, some women will not abort a pregnancy on moral grounds while others, adolescents in particular, choose the birthing option because the direct and indirect costs of obtaining an abortion are too high. Thus, increases in the shadow price of abortion, increase optimal family size and lessen the resources devoted to each child. Finally, advancements in prenatal diagnosis, such as amniocentesis and ultra sonography, yield very detailed information as to the health of the fetus. A)though pregnancies that are terminated because of this information are obviously unwanted, it is the health endowment of the fetus which is the underlying causal factor. 4

${ }^{3}$ The expected probability of aborting and the expected probability of delay are based on $F\left(X_{i 2} \hat{B}_{2}\right)$ and $X_{i 1} \hat{B}_{1}$ respectively.

${ }^{4} \mathrm{~A}$ fuller discussion of the unobservables that determine the probability of giving birth and their implications for infant health is presented by Grossman and Joyce (1988). 
The upshot is that there are numerous unobservables that impact on pregnancy resolution. Some yield predictions consistent with a wantedness mode1, and others do not. Trying to identify which is the dominant factor would require a more elaborate model as well as more data. We have emphasized the wantedness of a pregnancy because we feel it represents the most straightforward interpretation of the decision to abort or give birth. We acknowledge that some women who give birth describe their pregnancies as unwanted. 5 This means that the intensity of their subjective evaluation was insufficient to overcome the disutility, or high costs, of an abortion. Our choice of New York City should lessen the proportion of unwanted births due to the inaccessibility of abortion services. 6 Moreover, if the proportion of unwanted births is substantial, then the sign of the residual covariance will be biased towards zero or even positive. 7 The advantage of using pregnancy resolution as an indicator or wantedness is that pregnancies which are voluntarily terminated are clearly unwanted and in New York City, this represents a major portion of all pregnancies.

\footnotetext{
$5^{5}$ ata from the National Survey of Family Growth (NSFG) indicate that approximately 10 percent of cumulative births to ever-married women 15 to 44 in 1982 were described as unwanted. By race, 8 percent of white births and 22 percent of black births were unwanted at the time of conception (NCHS 1985).
}

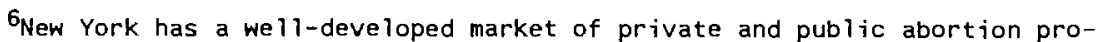
viders, an inexpensive system of mass transit, no parental notification laws and New York State is one of only 14 states that funds abortions for Medicaid eligible women. This explains in part why the proportion of pregnancies (live births plus induced abortions) in New York City that are terminated by induced abortion greatly exceeds national averages (see footnote 2).

${ }^{7}$ Specifically, women whose births were unwanted may have a higher than expected probability of giving birth $\left(u_{i 2}>0\right)$ but a greater than expected delay in the initiation of prenatal care $\left(u_{j 1}>0\right)$. This positive correlation among the residuals would lead to a rejection of a model based on wantedness. 
III. Data and Estimation

Data on births and abortions are from New York City vital statistics in 1984.8 In that year there were approximately 105,000 singleton live births and 89,000 induced abortion to New York City residents. Our analys is is based on randomly chosen subsamples of the combined population of births and induced abortions. Specifically, we subdivided the population into three race/ethnic groups and two age groups (less than 20 years of age and 20 years and older). The six groups and the number of observations in each group are as follows: white non-Hispanic adults $(11,589)$, black non-Hispanic adults $(11,106)$, Hispanic adults $(10,913)$, white non-Hispanic teenagers $(4,132)$, black non-Hispanic teenagers $(12,437)$ and $H$ ispanic teenagers $(8,266) .9$ Our analys is is made possible because many of the parental characteristics reported on the birth certificates are also reported on the induced termination records. Thus, by concatenating the data sets we were able to specify an equation predicting the probability of giving birth, given a woman was pregnant. A similar concatenation has been done by Powell-Griner and Trent (1987) and Joyce (1988) to study pregnancy resolution. A description of the variables is provided in Table 1 . The means and frequency distributions within each subsample are presented in

Be do not include women whose pregnancies were terminated by spontaneous abortion. Early spontaneous abortions are poorly reported. The New York City Department of Health reported 4,960 spontaneous abortions in 1984. This represented less than 4.4 percent of all live births. Yet data from the National Survey of Family Growth indicate that the ratio of spontaneous abortions to live births is greater than .21 (Pratt et al. 1984).

${ }^{9}$ For white and Hispanic adolescents the observations represent the entire population except for records that were deleted because of missing values. 
the Appendix.

Data from the abortion and birth certificates were augmented with 1980 census data which had been aggregated up from the census tract to the health area level. The health area is the smallest geographical area identified on the birth and abortion certificates. New York city is divided into 352 health areas. The average health area contains between 15,000 and 25,000 residents. The census data enabled us to calculate the percentage of persons below the poverty level in each health area by race and ethnicity.

The vital statistics were also augmented with variables that measure the availability of various reproductive health services. Combining data from the Alan Guttmacher Institute and the New York City Department of Health, we knew the number of family planning clinics, abortion providers, and prenatal clinics by health area in 1983. These availability measures were divided by the number of women 15 to 44 in a health area in 1980 . The denominators were from the 1980 census. A fourth availability measure was a dichotomous variable that equaled one if the woman lived in a health district in which was located a health center operated by the Supplemental Program for Women Infant and children (WIC).10

For most of the variables missing data were not considered a major problem. Except for previous induced and previous spontaneous abortions, less than three percent of the combined birth and abortion records lacked

${ }^{10}$ There are 30 health districts in New York City. Each contains approximately 10 health areas. 
data on the variables of interest. If the percent missing was evenly distributed by births and abortions we deleted these observations. In the case of parity and the method of finance one percent of the observations were missing on the induced termination records, but between 3 and 6 percent were missing on the birth records. To avoid altering the ratio of abortions to births, we substituted race/ethnic- and age-specific means for the unknowns.

A similar problem existed with previous spontaneous and previous induced abortions. On the abortion certificates approximately one percent of the records lacked data on previous induced abortions, but on the birth certificates the percent missing ranged from a low of 6 percent for white adolescents to a high of 21 percent for Hispanic adults. For spontaneous abortions approximately 3 percent of the abortion records lacked data but again the birth records showed a range of 4 percent missing for white adolescents and 23 percent for Hispanic adults. To preserve the ratio of abortions to births we substituted race/ethnic- and age-specific means for the unknowns.

Prenatal care is measured by the number of months a woman delays before seeking medical care for her pregnancy (equation 1). Women who received no care are assumed to have delayed 10 months. The birth probability equation has a dichotomous dependent variable: one if the woman gives birth, zero if she aborts (equation 2).

Equations (1) and (2) are estimated simultaneously by maximum likelihood. Although the two-step estimator proposed by Heckman (1976) is consistent, maximum likelihood estimates are more efficient. In order to 
identify the model at least one regressor from the prenatal care demand equation must not be included from the birth probability equation (Maddala 1983). Further, the model is on firmer ground if there are unique determinants of each equation. Thus, we assume that the availability of family planning clinics and abortion providers have no impact on the demand for prenatal care, and that the number of WIC centers and prenatal care clinics have little impact on the decision to give birth. In short, the cross-shadow price effects are restricted to be zero. Similarly, we exclude the number of previous induced abortions from the prenatal care demand equation since experience with abortion may represent a low psychic cost of an abortion or a high cost of contraception. We excluded parity from the birth probability equation because the left-hand side of the equation is in essence a measure of parity. However, we inciude parity, as well as late spontaneous abortions, in the prenatal care equation because they proxy experience with pregnancy and birth.

A unique feature of the New York City vital records is that the method of finance is included on both the birth certificates as well as the induced termination records. The three categories include Medicaid, se If pay and some other third party. With respect to prenatal care, we expect that women on Medicaid and women who paid for the birth themselves to delay the initiation of prenatal care longer than women enrolled in a Health Maintenance Organization (HMO), or some other third party. Women applying for Medicaid for the first time may experience delays in processing their applications. Moreover, all Medicaid recipients may face greater search costs since not all providers accept Medicaid due to the 
level of reinbursement. However, in the birth probability equation, it is unclear a priori whether Medicaid recipients are more likely to abort than non-Medicaid recipients. 11 New York State finances abortions for Medicaid eligible women and thus, the out-of-pocket costs are zero. Yet, Medicaid status clearly measures poverty. If the opportunity costs of giving birth are lower for poor than nonpoor women, then Medicaid status could be positively related to the probability of giving birth (Joyce 1988).

With respect to the areal measures, we would expect the poverty rate to be positively related to the probability of giving birth and positively related to prenatal care delay. The availability of abortion providers should increase the probability of aborting by lowering the indirect costs of accessing a provider. However, given New York City's well-developed mass transit system, neighborhood health facilities may be a less relevant availability measure. The same may apply to prenatal care and family planning clinics.

We have also included demographic characteristics of the mother. Among adults, older women should be more likely to abort since their pregnancies have a greater likelihood of being unplanned. For similar reasons unmarried women should be more likely to abort. With respect to prenatal care delay, unmarried women should proxy households headed by single women, especially among adults. Thus one would expect greater delay due to less income than households with two potential earners. The greater the level of schooling, the greater the opportunity costs of pregnancy and

11 In the birth probability equation the method of finance is reduced to two categories. Medicaid and all others. The selfpay category is difficult to interpret because third-party coverage of abortions is not common. However, among women who give birth, third party coverage more accurately 
childbearing and the greater the likelihood of abortion. Moreover, more educated women may access information regarding the availability of abortion more effectively than less educated women (Powel1-Griner and Trent 1987). Regarding prenatal care, more educated women, holding income constant, may be more aware of the epidemiological relationship between early care and birth outcomes. Thus, we would expect greater schooling to be negatively related to prenatal care delay (Cooney 1985; Rosenzweig and Schultz 1983).

Among adolescents, however, a number of the demographic characteristics may be endogenous. For instance, education may determine the probability of aborting, but the years of schooling completed could be affected by the time spent pregnant. Consequently, our measure of adolescent education is a dichotomous variable that equals one if a teenager has completed at least eight years of schooling and zero otherwise. Such a low cutoff should lessen the potential problems associated with reverse causality by capturing the adolescents whose educational problems existed before they became pregnant.

A similar problem exists with marital status. Vital statistics do not indicate whether a teenager conceived inside or outside of marriage. The distinction is potentially important because the decision to give birth can be made simultaneously with the decision to get married. For example,

reflects a well-insured individual. For example, among adult white women, 66 percent of the abortions, but only 10 percent of the births, were self pay (see Table A-1 in the Appendix). 
estimates for 1980 and 1981 reveal that 28 percent of the white filst births to adolescents and 8 percent of the black first births to adolescents were conceived premaritally but born inside of marriage (0'Connell and Rogers 1984). These figures are national estimates so their applicability to New York City is unclear. For example, the proportion of adolescent births born out-of-wedlock in New York City is substantially higher than the national figures.12 This suggests that the proportion of pregnancies conceived outside of marriage but delivered inside of marriage is probably less in New York. In particular, 93 percent of all black teenagers in New York City who gave birth in 1984 were unmarried (Table A1). The figures for whites and Hispanics are 50 and 75 percent respectively. Thus, for blacks the endogeneity of marital status in the birth probability equation appears unimportant. For Hispanics and whites we are unsure. This caveat should be kept in mind while interpreting the results.

\section{Results}

Maximum likelihood estimates of the birth probability equation and the prenatal care demand equation are presented in Tables 2 and 3 . The results for adolescents are in Table 2 and the results for adults are in Table 3. ordinary least squares estimates for the prenatal care demand equation are shown in Table 4 .

Regardless of age, race, or ethnicity, unmarried women and women with at least one previous induced abortion are much less likely to give birth

12 Nationally, 89 percent of all black live births and 43 percent of a 11 non-black live births to women 19 years and less were born out-of-wedlock. The non-black category includes the vast majority of Hispanic births (NCHS 1986). 
than their married or nulliparous counterparts. This is expected because unmarried women are more likely to have experienced an unintended or mistimed pregnancy (Pratt et al. 1984). The result with respect to previous induced abortions is consistent with the interpretation that the psychic costs of abortion are less for women who have aborted in the past. Moreover, these women may be more willing to use abortion as a substitute for contraception.

Women who are covered by Medicaid have a greater likelihood of giving birth than women not supported by Medicaid. Again, the finding pertains to all women regardless of age, race, or ethnicity; however. Medicaid status has a much greater impact on the probability of giving birth among adolescents than it does for adults as measured by the magnitude of the coefficients. The results for adolescents are similar to findings from a recent study of adolescents in California (Leibowitz, Eisen, and Chow 1986). The finding is notable because for women on Medicaid the out-of-pocket costs for an abortion are zero. One interpretation, therefore, is that economic support for adolescent childbearing as provided by Medicaid and Welfare is a disincentive for pregnant teenagers contemplating an abortion. However, as Joyce (1988) argues, disentangling the economic causes of adolescent pregnancy resolution from the emotional and psychological ones may require more refined data.

Adult women with at least twelve years of schooling are more likely to terminate a pregnancy than are women with between nine and eleven years of schooling. A similar finding has been reported before (Powell-Griner and Trent 1987). In addition, previous pregnancy loss among adult women is 
positively associated with giving birth. Very young teens are more likely to abort than are older adolescents irrespective of race and ethnicity. Except for Hispanics, older adult wonen are more likely to abort than their younger counterparts.

Among the areal characteristics, the availability of abortion providers has the correct sign among whites but is statistically significant only for adults. Among black adults the sign is positive and significant. Hispanic adolescents living in neighborhoods of relative poverty have a greater than average propensity to give birth; white adults residing in similar neighborhoods are more likely to abort. Differences among Hispanics with respect to pregnancy resolution are pronounced. Cubans have a greater likelihood of aborting than do Puerto Ricans, but Mexicans as well as Central and South Americans are more likely to carry to term. One explanation for the variations may be the degree of assimilation among the various groups (Ortiz 1987: Schur, Bernstein and Berk 1987).

Ignoring the impact of pregnancy resolution, the results for the prenatal care demand equations are in general conformity with the literature. More educated adult women delay less irrespective of race and ethnicity ${ }^{13}$ (Taffel 1980; Rosenzweig and Schultz 1983). Women in areas of above average poverty initiate care later than women from less poor neighborhoods (Joyce 1987a). Residence in a health district with a WIC center is associated with less delay for black women while neighborhood prenatal care clinics are positively related to delay among Hispanic adults. Finally.

\footnotetext{
${ }^{13}$ The one exception is Hispanic adults in which women with less than 9 years of schooling delay approximately one-third of a month less than women with between 9 and 11 years schooling.
} 
except for Hispanic teenagers, women on Medicaid, or women with no health insurance begin prenatal care later than women with some other form of health insurance (Cooney 1985; General Accounting Office 1987).

Regarding other characteristics of the mother, older adult women delay less, while very young adolescents delay more than women in the respective reference categories. Unmarried women begin care later than married women and the differential is greatest for whites and smallest for blacks. Greater fertility is associated with greater delay and women who have experienced a late spontaneous abortion respond no differently than women with no such history. Finally, as in the birth probability equation, there is substantial variation among Hispanic subgroups. Mexicans and Central and South Americans are more likely to delay prenatal care relative to Puerto Ricans: Cubans and other Mispanics delay less.

The presence of selectivity bias is measured by the residual covariance $\left(\sigma_{12}\right)$ between equations (1) and (2). We find evidence of selectivity bias in the prenatal care demand equations for blacks and Hispanics irrespective of age although for black adults, the null hypothesis of selectivity bias can be rejected at only the .07 level. There is no evidence of such bias among whites. Put differently, holding variations in demographic characteristics, years of completed schooling, neighborhood poverty, and method of finance, we find that black and Hispanic women who give birth represent a non-random draw from the population of pregnant women. The negative covariance indicates that, on average, the unobserved factors which raise the probability of giving birth are positively correlated with the unobserved factors that decrease delay in the initiation of prenatal care. It 
is our contention that by controlling for self-selection into the birth sample, we are controlling, in part, for the wantedness of the pregnancy. The negative covariance between the residuals in the pregnancy resolution equation and the prenatal care demand equation is consistent with the interpretation that pregnancies that are more wanted, delay the initiation of prenatal care less.

What these results imply about white pregnant women is that the decision to abort or give birth yields no information regarding the utilization of prenatal care. One explanation is that we have no equation predicting the probability of becoming pregnant. If whites use contraception more often than blacks, and a number of sources indicate that they do, then the selection process which reduces the proportion of unplanned pregnancies may occur at an earlier point in the reproductive cycle among whites than it does for blacks (Henshaw et a1. 1985; Pratt et a 1. 1984; Stephen, Rindfuss and Bean 1988). Thus, by analyzing only pregnant women, as opposed to sexually active women, we are unable to incorporate the impact of contraception on prenatal behavior.

One means of gauging the magnitude of the selection effect on the initiation of prenatal care is to compare the observed mean number of months a woman delays before initiating care to the expected mean delay of women who aborted had they chosen to give birth. Our first comparison is based on unobserved factors only. 14 Ignoring the results for whites, we find that black teenagers who aborted would have delayed the initiation of care 1.5

14 Let $M_{b}$ be the observed mean number of months a woman delays before initiating prenatal care. Let $M_{\mathrm{a}}$ be the expected delay in months that we would have observed among women who aborted had they chosen to give birth. 
months more than the mean number of months delayed that were actually observed for black adolescents. Hispanic adolescents who aborted would have delayed .8 of a month more than what was observed. The relevant figures for black and Hispanic adults are .4 and .7 months respectively. If we allow for differences in both observed and unobserved characteristics between women who gave birth and women who aborted the results change slightly.15 Hispanic adolescents who aborted would be expected to delay 1.0 months more than their counterparts who gave birth; black adults who aborted would delay the initiation of prenatal care, on average, .5 of a month more. There were no changes for black adolescents and Hispanic adults. As the results make clear, the expected differences in the initiation of prenatal care between aborters and those who give birth are dominated by the unobserved characteristics.

Let $\bar{X}_{b}$ and $\bar{X}_{a}$ be the means of the determinants of $M_{b}$ and $M_{a}$ respectively and let $\hat{B}_{1}$ be the estimated vector of coefficients. Correcting for the selection, the difference between $M_{b}$ and $M_{a}$ is:

$$
M_{b}-M_{a}=\left(\bar{X}_{b}-\bar{X}_{a}\right) \hat{B}_{1}+\frac{\hat{\sigma}_{12}}{\sigma_{2}}\left(\hat{\lambda}_{b}-\hat{\lambda}_{a}\right)
$$

where $\hat{\lambda}_{b}$ is the estimated inverse Mill's ratio associated with those who give birth $\left(\hat{\lambda}_{b}>0\right)$ and $\hat{\lambda}_{a}$ is the estimated inverse Mill's ratio associated with those who abort $\left(\hat{\lambda}_{a}<0\right)$. The estimates of $\hat{\lambda}_{b}$ and $\hat{\lambda}_{a}$ are shown in Table $A 1$ in the Appendix. Assuming $\bar{x}_{b}=\bar{x}_{a}$ yields the effect of unobservables alone on prenatal care delay.

15These calculations differ from the previous ones in that $x_{b}$ and $x_{a}$ in equation (5) of footnote 14 are allowed to differ. 
Failure to correct for self-selection can yield biased estimates as shown by comparing the corrected with the uncorrected results in Table 4. Among adults, for instance, the impact of completing high school on prenatal care delay falls by 27 percent among black adults and 17 percent among Hispanic adults. For black adolescents the differential delay between those on Medicaid and those with some other third party coverage falls 62 percent when self-selection is corrected. However, in the case of Hispanic adolescents the same differential increases by 41 percent. The most dramatic change between the corrected and uncorrected estimates occurs for unmarried women. Among blacks of all ages the coefficients on out-ofwedlock births more than doubles; for Hispanics the same coefficient increases by more than 50 percent when corrected for self-selection. The results imply that unmarried women who do not voluntarily terminate the ir pregnancies are at a greater risk of inadequate prenatal care than would be predicted by direct correlational methods. The results are especially worrisome given the rise in out-of-wedlock childbearing among women of Hispanic descent.

\section{Conclusion}

In this study we have attempted to incorporate the information as to how a pregnancy is resolved into the prenatal care demand equation. We accomplished this by treating women who give birth as a self-selected sample from the population of pregnant women. However, instead of simply testing for selectivity bias, we have argued that the sign of the residual covariance between the pregnancy resolution equation and the prenatal care 
demand equation may offer useful insights as to the effect of unobservables on the demand for prenatal care. In particular, women with a higher than expected probability of giving birth, evidence a smaller than expected delay in the initiation of prenatal care. The result is consistent with the interpretation that women whose pregnancies are more wanted, obtain prenatal care earlier than women whose pregnancies are less wanted.

We found that the black and Hispanic women who give birth differ in a statistically significant manner from their counterparts who abort. We observed no such differences for whites. We have speculated that black and Hispanic women may substitute abortion for contraception more frequently than white women. As a result, the selection mechanism encouraged by abortion has a greater impact on the prenatal behavior of minorities than it has among whites.

It must be noted that New York City is a rather unique setting. It has a wel1-developed market of private and public providers, a state government that continues to fund abortions for all Medicaid-eligible women, no parental notification laws with respect to minors, and a readily available system of transportation. At the same time the shadow price of contraception may be higher for minorities than for whites due to language barriers, lower levels of schooling, and less access to private gynecological care. Given these factors, the shadow price of abortion relative to contraception may be lower for black and Hispanic women which would induce greater substitution away from contraception towards abortion.

The upshot is that the results reported here may not generalize to other areas where the shadow price of abortion is higher. Consequently, an 
agenda for future research would be to conduct a similar analysis in other states where abortion services are less accessible. A higher shadow price of abortion would either promote greater contraceptive use or result in more unwanted births. The latter outcome is more likely for adolescents and minorities given the frequency with which contraception is used by these groups (Pratt et al. 1984).

Another area of future research is to examine the impact of pregnancy resolution on birth outcomes. Given the positive association between early prenatal care and birth outcomes (Institute of Medicine 1985), the results reported here suggest an important indirect effect of pregnancy resolution on birth outcomes through its impact on prenatal care. However, wantedness, as captured by pregnancy resolution, may improve other prenatal behaviors (Weller, Eberstein and Bailey 1987). The result could be a direct effect on birth outcomes if pregnancies that are more wanted are positively related to such hard to measure inputs as exercise, nutrition, and lower levels of stress. 
Table 1

Description of Variables

Prenatal care delay

Induced abortions

Spontaneous abortions

Late spontaneous abortions

Parity

Age $<18$

Age 35 to 39

Age 40 and over

Education $<9$

Education $=12$

Education $>12$

Out-of-wedlock

Medicaid

Self-pay

Family planaing clinic

Abortion providers

Prenatal care clinics

WIC center

Poverty
The number of months from when a woman conceived until she made her first prenatal care visit

The number of previous induced abortions

The number of previous spontaneous abortions (includes fetal deaths)

The number of previous spontaneous abortions that occurred after the 19 th week of gestation

Number of previous live births

A dichotomous variable that equals ore if the woman is less than 18 years old

A dichotomous variable that equals one if the woman is 35 to 39 years of age

A dichotomous variable that equals one if the woman is 40 years or older

A dichotcmous variable that equals one if the woman completed less than nine years of schooling

A dichotomous variable that equais one if the woman completed twelve years of schooling

A dichotomous variable that equals one if the woman completed more than twelve years of schooling

A dichotomous variable that equals one if a woman is not married

A dichotomous variable that equals one if the abortion or birth was financed by Medicaid

A dichotomous variable that equals one if the abortion or birth was self-financed

The number of family planning clinics per 10,000 women 15 to 44 in a health area

The number of abortion providers per 10,000 women 15 to 44 in a health area

The number of prenatal care clinics per 10,000 women 15 to 44 in a health area

A dichotomous variable that equals one if the woman resided in a health area district that contained an office for the Supplemental Nutrition Program for Women, Infants and Children

The race- and ethnic-specif ic percentage of people below the poverty level in 1980 in a health area; measure for whites includes both white Hispanics and white non-Hispanics; similar comment applies to measure for blacks 
Table 2

\begin{tabular}{|c|c|c|c|c|c|c|}
\hline \multicolumn{7}{|c|}{ 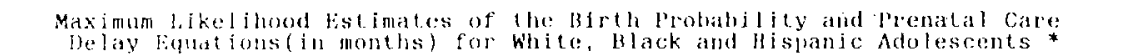 } \\
\hline & \multicolumn{2}{|c|}{ Whites } & \multicolumn{2}{|c|}{ Blacks } & \multicolumn{2}{|c|}{ llispanics } \\
\hline & $\begin{array}{l}\text { lipllit } \\
\text { probalility }\end{array}$ & $\begin{array}{l}\text { Preenatal } \\
\text { care }\end{array}$ & $\begin{array}{l}\text { Birth } \\
\text { probability }\end{array}$ & $\begin{array}{l}\text { Prenatal } \\
\text { care }\end{array}$ & $\begin{array}{l}\text { Birch } \\
\text { probiatilit: }\end{array}$ & $\begin{array}{l}\text { Prenatal } \\
\text { y care }\end{array}$ \\
\hline Intercept & 0.916 & 3.706 & 0.364 & 5.135 & 0.227 & \\
\hline Abortion providers & $\begin{array}{r}(13.24) \\
-0.033\end{array}$ & & $\begin{array}{l}(5.76) \\
0.010\end{array}$ & & $\begin{array}{l}(3.32) \\
0.012\end{array}$ & $(18.98)$ \\
\hline Fam planning clin & $\begin{array}{l}(-1.35) \\
-0.016\end{array}$ & & $\begin{aligned}(0.87) \\
0.005\end{aligned}$ & & $\begin{array}{l}(0.97) \\
-0.003\end{array}$ & \\
\hline Prenatis care clin & $(-0.93)$ & -0.010 & $(0.91)$ & 0.012 & $(-0.56)$ & -0.021 \\
\hline 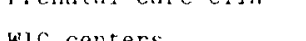 & & $(-0.14)$ & & $(0.53)$ & & $(-0.91)$ \\
\hline wlc centers & & $\begin{array}{l}0.075 \\
(0.47)\end{array}$ & & $\begin{array}{l}-0.226 \\
(-2.94)\end{array}$ & & $\begin{array}{l}-0.111 \\
(-1.33)\end{array}$ \\
\hline Poverty rate & 0.001 & -0.009 & 0.002 & 0.008 & 0.012 & 0.010 \\
\hline Medicaid & $\begin{array}{r}10.497 \\
1.028\end{array}$ & $\begin{array}{r}(-1.24) \\
0.761\end{array}$ & $\begin{array}{l}1.80) \\
0.517\end{array}$ & $\begin{array}{l}2.281 \\
0.289\end{array}$ & $\begin{array}{l}9.077 \\
0.377\end{array}$ & $\begin{array}{r}(2.40) \\
-0.372\end{array}$ \\
\hline Self pay & & $\begin{array}{l}(3.05) \\
1.335\end{array}$ & & $\begin{array}{r}(2.45) \\
1.243\end{array}$ & $(10.97)$ & $\begin{array}{r}(-3.05) \\
0.235\end{array}$ \\
\hline Total spon. abortions & 0.270 & $(6.82)$ & 0.078 & $(8,96)$ & 0.022 & $(1.41)$ \\
\hline 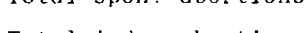 & $(1.98)$ & & $(1.48)$ & & $(0.34)$ & \\
\hline Total indu abortions & $\begin{array}{r}-0.653 \\
(-18.14)\end{array}$ & & $\begin{array}{r}-0.486 \\
(-24.99)\end{array}$ & & $\begin{array}{r}-0.701 \\
(-30.97)\end{array}$ & \\
\hline Schooling & $\begin{array}{r}0.272 \\
(2.72)\end{array}$ & $\begin{array}{l}0.459 \\
(1.85)\end{array}$ & $\begin{array}{l}-0.038 \\
(-0.76)\end{array}$ & $\begin{array}{r}0.824 \\
(5.05)\end{array}$ & $\begin{array}{r}0.352 \\
(7.15)\end{array}$ & $\begin{array}{l}-0.159 \\
(-1.27)\end{array}$ \\
\hline Age $<18$ & -0.113 & 0.489 & $\begin{array}{r}-0.249 \\
-10.249\end{array}$ & 0.337 & -0.130 & 0.289 \\
\hline Late spon. abortions & & $\begin{array}{l}1.131 \\
1.280\end{array}$ & $(-10.14)$ & $\begin{array}{r}14.111 \\
-0.343\end{array}$ & $(-4.10)$ & -0.172 \\
\hline Out-of-wedlock & -1.939 & 1.170 & -0.714 & 0.742 & -0.882 & 0.676 \\
\hline Parity & & 0.209 & & 0.340 & & 0.419 \\
\hline Central/South Amer. & & & & & $\begin{array}{r}0.393 \\
(8.43)\end{array}$ & $\begin{array}{l}0.04) \\
(0.77)\end{array}$ \\
\hline Mexican & & & & & 0.599 & 0.550 \\
\hline Cuban & & & & & -0.382 & 0.732 \\
\hline other hispanies & & & & & $\begin{array}{r}(-2.71) \\
0.040\end{array}$ & $\begin{array}{l}(1.36) \\
-0.584\end{array}$ \\
\hline 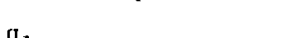 & & & & & $(0.58)$ & $(-2.60)$ \\
\hline & & $(35.88)$ & & $(43.47)$ & & $(51.85)$ \\
\hline $0_{1:}$ & & 0.112 & & $\begin{array}{l}-0.858 \\
(-4.15)\end{array}$ & & $\begin{array}{l}-0.512 \\
(-2.08)\end{array}$ \\
\hline Log likelihood & -4499.5 & & -20146 & & -15727 & \\
\hline
\end{tabular}

*/ Asymptotic $t$ statistics in parentheses, $o_{2}$ is the standard deviation in prenatal care delay equation and $\sigma_{12}$ is the residual covariance between the birth probability and prenatal care delay equations. 
Table: :3

Maxlmum likelilood list.jmates of the Birth Probabit ity and prenatal Care belay Equations (in months) for White. Black and Hispanif; Adults *

\section{Whites}

Uixth prenatal probablitite care

Intercept
Abortion providers
Fam plaming clin
Prenatal care clin

WIC centers

Poverty rate

Medicaid

self pay

Total spon. abortions

Total indu, abortions

Schooling $<9$

Schooling $=12$

Schooling $>12$

Age 35 to 39

Age 40 to 44

Late spon. abortions

out-of-wedlock

Parity

Central/South Amer.

Mexican

Cuban

other hispanics

$\sigma_{1}$

$\sigma_{12}$

Log likelihood

1.523
$(25.40)$
-0.026
$(-2.18)$
-0.006
$(-0.59)$

$(-0.83)$

-0.004
$(-2.49)$

0.352

(8.31)

0.092

(3.56)

$-0.560$

$(-46.94)$

$-0.546$

$(-5.32)$
-0.262

$(-4.79)$

$-0.173$

$(-3.03)$

$-0.048$

$(-1.11)$

$-0.595$

$(-7.56)$

-1.915
$(-57.52)$
$-0.013$

$-0.006$

$(-0.13)$

3.306
$(39.47)$

0.014

$(6.25)$

$(19.43)$

0.478

$(8.47)$

0.335

(2.86)

$-0.493$

$(-6.84)$

$-0.596$

$(-7.76)$

$-0.084$

$(-1.24)$

$-0.240$

$(-1.39)$

$-0.057$

$(-0.24)$

0.885

(7.91)

0.096
$(6.38)$

\section{Blacks}

Rirth Prenatal profability
II Is panjes

[jirth Prenata] probability care
4.186
$(26.67)$

$-0.034$

$(-1.61)$

$-0.355$

$(-4.99)$

$0.000 \quad 0.019$

$(0.32) \quad(6.04)$

$0.163 \quad 0.885$

$(5.62) \quad(10.11)$

1.16

1.161
$(9.66)$

0.127

(5.70)

$-0.447$

$(-42.04)$

0.461
$(5.14)$

$(5.14)$
-0.420

$(-11.50)$

$-0.226$

$(-5.49)$

$(-1.83)$

$(-1.83)$
-0.404

$(-4.23)$

-0.654
$(-22.48)$

$-0.188$

$(-0.97)$

$-0.120$

$(-2.05)$

$-0.538$

$(-4.90)$

$-0.298$

$(-2.07)$

$-0.230$

$(-0.71)$

$(-0.43)$

$-0.43)$
0.203

(2.08)

0.180

(7.03)

$$
\begin{array}{rr}
0.779 & 4.051 \\
(13.47) & (25.09) \\
-0.005 & \\
(\cdots 0.45) & \\
0.022 & \\
(3.69) &
\end{array}
$$

0.052

(2.96)

$-0.119$

$(-1.80)$

$\begin{array}{ll}0.001 & 0.020\end{array}$

$(1.28) \quad(6.92)$

$\begin{array}{ll}0.118 & 0.478\end{array}$

$(3.80) \quad(6.23)$

0.714

$(6.37)$

0.061

$(2.25)$

$-0.53$

$(-49.13)$

$0.221-0.368$

$(4.32) \quad(-3.67)$

$\begin{array}{lll}-0.340 & -0.419\end{array}$

$(-9.84) \quad(-5.18)$

$\begin{array}{ll}-0.360 & -0.666\end{array}$

$(-8.29) \quad(-6.21)$

$0.100-0.437$

$(1.93)(-3.65)$

$0.046-0.493$

$(0.44)(-1.74)$

$-0.113$

$(-0.46)$

$-0.652 \quad 0.504$
$0.12)$

$(-22.32) \quad(6.12)$

0.087

(3.54)

$0.662 \quad 0.306$

$(20.35) \quad(3.60)$

$0.463 \quad 0.550$
$(3.19)$

(3.19) (2.17)

$-0.217 \quad-0.301$

$(-2.42) \quad(-0.89)$

$0.371-0.438$

(6.13) (-2.59)

2.512

(75.25)

$-0.432$

$(-3.29)$ */ Asymptotic $t$ statistics in parentheses. $\sigma_{2}$ is the standard deviation in birth probability and prenatal care delay equations. 
Table 4

Ordinary Least Squares Estimates of the Irenatal Care Dolay Equations(in months) by Age, Race, and Ethnicity *

\begin{tabular}{|c|c|c|c|c|c|c|}
\hline & \multicolumn{2}{|c|}{ Whites } & \multicolumn{2}{|c|}{ Blacks } & \multicolumn{2}{|c|}{ Hispanics } \\
\hline & Teens & Adul ts & Teens & Adults & Tecms & Adults \\
\hline \multirow[t]{2}{*}{ Constant } & 3.753 & 3.311 & 4.536 & 4.093 & 4.900 & 3.840 \\
\hline & $(24.97)$ & $(23.34)$ & $(26.99)$ & $(28.06)$ & $(25.67)$ & $(27.87)$ \\
\hline \multirow[t]{2}{*}{ Schooling $<9$} & 0.444 & 0.340 & 0.824 & -0.140 & -0.059 & -0.336 \\
\hline & $(1.68)$ & $(2.01)$ & $(5.26)$ & $(-0.72)$ & $(-0.50)$ & $(-3.21)$ \\
\hline \multirow[t]{2}{*}{ Schooling $=12$} & & -0.490 & & -0.264 & & -0.483 \\
\hline & & $(-5.10)$ & & $(-2.69)$ & & $(-5.93)$ \\
\hline \multirow[t]{2}{*}{ Schooling > 12} & & -0.594 & & -0.580 & & -0.741 \\
\hline & & $(-6.06)$ & & $(-5.25)$ & & $(-7.21)$ \\
\hline \multirow[t]{2}{*}{ Medicaid } & 0.701 & 1.239 & 0.588 & 0.909 & -0.273 & 0.506 \\
\hline & $(4.32)$ & $(14.44)$ & $(6.78)$ & $(10.38)$ & $(-2.47)$ & $(6.56)$ \\
\hline \multirow[t]{2}{*}{ Self Pay } & 1.333 & 0.477 & 1.307 & 1.169 & 0.256 & 0.720 \\
\hline & $(6.62)$ & $(7.24)$ & $(3.60)$ & $(9.48)$ & $(1.58)$ & $(6.37)$ \\
\hline \multirow[t]{2}{*}{ Poverty } & -0.009 & 0.014 & 0.009 & 0.019 & 0.014 & 0.020 \\
\hline & $(-1.28)$ & $(5.53)$ & $(2.94)$ & $(5.99)$ & $(3.79)$ & $(7.37)$ \\
\hline \multirow[t]{2}{*}{ Late spon. abortions } & 1.304 & -0.057 & -0.254 & -0.060 & -0.115 & -0.124 \\
\hline & $(1.20)$ & $(-0.25)$ & $(-0.47)$ & $(-.30)$ & $(-0.16)$ & $(-0.46)$ \\
\hline \multirow[t]{2}{*}{ Age < 18} & 0.495 & & 0.229 & & 0.266 & \\
\hline & $(3.10)$ & & $(3.01)$ & & $(3.02)$ & \\
\hline \multirow[t]{2}{*}{ Age 35 to 39} & & -0.083 & & -0.301 & & -0.420 \\
\hline & & $(-1 \cdot 33)$ & & $(-2.25)$ & & $(-3.67)$ \\
\hline \multirow[t]{2}{*}{ Age $>39$} & & -0.234 & & -0.272 & & -0.480 \\
\hline & & $(-1.57)$ & & $(-0.98)$ & & $(-2.00)$ \\
\hline \multirow[t]{2}{*}{ Out of wedlock } & 1.293 & 0.913 & 0.377 & 0.098 & 0.452 & 0.358 \\
\hline & $(8.64)$ & $(11.53)$ & $(2.65)$ & $(1.27)$ & $(4.65)$ & $(5.19)$ \\
\hline \multirow[t]{2}{*}{ Parity } & 0.211 & 0.096 & 0.323 & 0.174 & 0.409 & 0.079 \\
\hline & $(1.19)$ & $(5.69)$ & $(5.41)$ & $(6.51)$ & $(5.26)$ & $(3.08)$ \\
\hline \multirow[t]{2}{*}{ WIC center } & 0.074 & -0.006 & -0.221 & -0.354 & -0.111 & -0.116 \\
\hline & $(0.47)$ & $(-0.14)$ & $(-2.88)$ & $(-4.95)$ & $(-1.31)$ & $(-1.72)$ \\
\hline \multirow[t]{2}{*}{ Prenatal care clinics } & -0.007 & -0.013 & 0.016 & -0.031 & -0.022 & 0.057 \\
\hline & $(-0.10)$ & $(-0.87)$ & $(0.75)$ & $(-1.41)$ & $(-0.90)$ & $(2.96)$ \\
\hline \multirow[t]{2}{*}{ Cen/South Americans } & & & & & 0.217 & 0.447 \\
\hline & & & & & $(1.89)$ & $(6.30)$ \\
\hline \multirow[t]{2}{*}{ Mexican } & & & & & 0.678 & 0.666 \\
\hline & & & & & $(2.34)$ & $(2.63)$ \\
\hline \multirow[t]{2}{*}{ Cuban } & & & & & 0.610 & -0.361 \\
\hline & & & & & $(1.30)$ & $(-1.39)$ \\
\hline \multirow[t]{2}{*}{ Other Hispanics } & & & & & -0.565 & -0.356 \\
\hline & & & & & $(-2.76)$ & $(-2.57)$ \\
\hline F statistic & 19.88 & 85.0 & 19.81 & 38.50 & 7.41 & 32.16 \\
\hline R squared (adjusted) & 0.134 & 0.129 & 0.035 & 0.090 & 0.020 & 0.076 \\
\hline Observations & 1225 & 7361 & 5201 & 4924 & 4482 & 6475 \\
\hline
\end{tabular}

* T statistics are in parentheses 
Cooney, Joan P. "What Determines the Start of Prenatal Care?" Medical Care 23 (August 1985): 986-997.

Corman, Hope, and Grossman, Michael. "Determinants of Neonatal Mortality

Rates in the U.S.: A Reduced Form Moder." Journal of Health Economics

4 (September 1985): 213-236.

Darabi, Katherine F., and Ortiz, Vilma. "Childbearing among Young Lat ino Women in the United States." American Journal of Public Health 77 (January 1987): 25-28.

General Accounting Office, "Prenatal Care. Medical Recipients and Uninsured Women Obtain Insufficient Care." Report to the Chairman, Subcomittee on Human Resources and Intergovernmental Relations, Committee on Government Operations, House of Representatives. HRD-87-137. Washington, D.C.: U.S. Government Printing office, 1987. Greene, William H. "Sample Selection Bias as a Specification Error: Comment." Econometrica 49 (May 1981): 795 798.

Grossman, Michael, and Jacobowitz, Stephen. "Variations in Infant Mortality Rates among Counties of the United States: The Roles of Public Policies and Programs." Demography, 18 (1981): 695-713. Heckman, James J. "The Common Structure of Statistical Models of Truncation, Sample Selection, and Limited Dependent Variables and a Simple Estimator for Such Models." Annals of Economic and Social Measurement 5 (Fal1 1976): 475-492.

Heckman, James J. "Sample Selection Bias as a Specification Error." Econometrica 47 (January 1979): 153-161. 
Henshaw, Stanley K.; Darroch Forrest, Jacqueline; and Blaine, Ellen.

"Abortion Services in the United States, 1981 and 1982." Family

Planning Perspectives 16 (May/June 1984): 119-127.

Hofferth, S.L. "Teenage Pregnancy and its Resolution." In Risking The

Future: Adolescent Sexuality, Pregnancy, and Childbearing, edited by

National Research Council, Vol. II. Washington, D.C.: National

Academy Press, 1987.

Institute of Medicine. Preventing Low Birthweight. Washington, D.C.:

National Academy Press, 1985.

Joyce, Theodore. "The Impact of Induced Abortion on Black and White

Birth Outcomes in the United States." Demography 24 (May 1987):

229-244.

Joyce, Theodore. "The Demand for Health Inputs and Their Impact on the

Black Neonatal Mortality Rate in the U.S." Social Science Medicine 24, (1987): 911-918.

Joyce, Theodore J. "The Social and Economic Correlates of Pregnancy

Resolution Among Adolescents in New York City by Race and Ethnicity:

A Multivariate Analysis." American Journal of Public Health 78

(June 1988): 626-631.

Klerman, Lorraine V., and Jekel, James F. "Unwanted Pregnancy." in

Perinatal Epidemiology, edited by Michael B. Bracken, pp. 283-300.

New York, N.Y.: Oxford University Press, Inc., 1984.

Leibowitz, Arleen; Eisen, Marvin; and Chow, Winston K. "An Economic Model

of Teenage Pregnancy Decision-Making." Demography 23 (February 1986):

67-77. 
Maddala, G.S. Limited Dependent and Qualitative Variables in Econometrics.

Econometric Society Monographs No. 3. New York, NY: Cambridge University Press, Inc., 1983.

Marsiglio, William, and Mott, Frank L. "Does Wanting to Become Pregnant with a First Child Affect Subsequent Maternal Behaviors and Infant Birth Weight?" Forthcoming in the Journal of Marriage and the Family 50 (November 1988).

National Center for Health Statistics, W.F. Pratt and M.C. Horn: "Wanted and Unwanted Childbearing: United States, 1973-82." Advance Data From Vital and Health Statistics. No. 108 DHHS Pub No. (PHS) 85-1250. Public Health Service. Hyattsville, Md., May 1985.

National Center for Health Statistics. Advanced Report of Final Natality Statistics, 1984. Monthly Vital Statistics Report, Vol. 35, No. 4 Supp. DHHS Pub. No. (PHS) 86-1120. Public Health Service. Hyattsville, MD .

National Center for Health Statistics, E. Powell-Griner: Induced Terminations of Pregnancy: Reporting States, 1984. Monthly Vital Statistics Report. Vol. 36, No, 5, Supp. (2). DHHS Pub. No. 87-1120. Public Health Service. Hyattsville, Md. September 8, 1987. Powe 1]-Griner, Eve, and Trent, Katherine. "Sociodemographic Determinants of Abortion in the United States." Demography 24 (November 1987): 553-561.

Pratt, William F.; Mosher, William D.; Bachrach, Christine A.; and Horn, Majorie C. "Understanding U.S. Fertility: Findings from the National Survey of Family Growth, Cycle III." Population Bulletin 39, 1984. 
Rosenzweig, Mark R., and Schultz, T. Paul. "Consumer Demand and Household Production: The Relationship Between Fertility and Child Mortality." American Economic Review 73 (May 1983) 38-42.

Schur, Claudia L.; Bernstein, Amy B.; and Bork, Marc L. "The Importance of Distinguishing Hispanic Subpopulations in the Use of Medical Care." Medical Care 25 (July 1987): 627-641.

Stephen, Elizabeth Hervey; Rindfuss, Ronald R.; and Bean, Frank D. "Racial Differences in Contraceptive Choice: Complexity and Implications." Demography 25 (February 1988): 53-70.

Taffel, S. Factors Associated with Low-Birth Weight: United States, 1976.

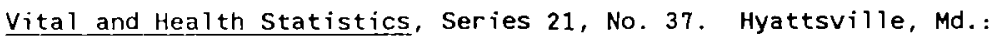
U.S. Department of Health, Education and Welfare. 1980.

U.S. Department of Health and Human Services. Report of the Secretary's Task Force on Black and Minority Health. Volume VI: Infant Mortality and Low Birthweight. Washington, D.C.: U.S. Government Printing office, January 1986 .

Weller, Robert H.; Eberstein, Isaac W.; and Bailey, Mohamed. "Pregnancy Wantedness and Maternal Behavior During Pregnancy." Demography 24 (August 1987): $407-412$.

Willis, Robert J. "A New Approach to the Economic Theory of Fertility Behavior." Journal of Political Economy 81 (March/April 1973: S14-S64. 
Alymad1:

inila $\hat{x}$

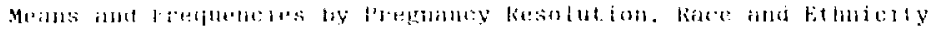

\begin{tabular}{|c|c|c|c|c|c|c|}
\hline \multirow[t]{2}{*}{ Aduils } & \multicolumn{2}{|c|}{ Wis is os } & \multicolumn{2}{|c|}{ 1:1 inek: } & \multicolumn{2}{|c|}{ Il ispituits } \\
\hline & Hathes & Alual inas & Hirths & Abortions & lairtis & Nometions \\
\hline 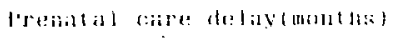 & $\therefore, 29$ & & 1. $3:$ & & 4.98 & \\
\hline 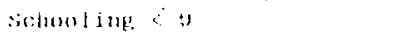 & (1): & $(1 !)$ & .01 & .14 .4 & .15 & .06 \\
\hline schoul ing : $: 12$ & .4 .4 & $.14:$ & $A n$ & .57 & .41 & .25 \\
\hline schout infe > 12 & .40 & $4 i$ & $\therefore 1$ & .28 & .13 & .21 \\
\hline Medicald & $0 \%$ & .14 & .16 & .46 & $5:$ & $\therefore 60$ \\
\hline sete pay & .10 & $.6 E$ & .10 & .32 & .10 & $\therefore z$ \\
\hline froverly & 12.13 & $1: 1.60$ & 24.30 & $\because 4.76$ & $\therefore 6.46$ & $\therefore(; .0 !)$ \\
\hline folal afmontaneous allarel lans & .17 & .12 & .2心 & .17 & .16 & .15 \\
\hline lotall inducera abontions & $.0 !$ & & .01 & & $\therefore$ & 1.21 \\
\hline Late spontaneous abortions & .17 & & .22 & & .41 & \\
\hline Age $\quad 35$ to 30 & .12 & .10 & (4) & .04 & $.0 ! 3$ & .07 \\
\hline Age $>: 9$ & .02 & .02 & .02 & .02 & .02 & .01 \\
\hline out of wedlock & $.0: 3$ & 60 & .55 & .76 & .44 & .71 \\
\hline Abortion providers & .63 & .73 & .00 & .54 & .60 & .57 \\
\hline lamily planning clinics & .74 & .94 & 1.41 & 1.36 & 1.65 & 1.43 \\
\hline Parity & .86 & .76 & 1.26 & 1.52 & 1.22 & 1.53 \\
\hline WIC conters & .30 & .29 & .57 & .54 & .41 & .46 \\
\hline Frenatal care clinics & .67 & .70 & 1.04 & .66 & .96 & 87 \\
\hline Centralisouth Americans & & & & & .48 & .10 \\
\hline Mexican & & & & & .02 & .01 \\
\hline Cuban & & & & & .02 & .03 \\
\hline Other Hispanics & & & & & .06 & .05 \\
\hline Inverse Mill's ratjo & .34 & .59 & .74 & .60 & .50 & .73 \\
\hline Observations & 7361 & 4230 & 4924 & 6092 & 6475 & 4438 \\
\hline Teenagers & $\begin{array}{l}\text { White } \\
\text { Qirths }\end{array}$ & $\begin{array}{l}\text { es } \\
\text { Abortions }\end{array}$ & $\begin{array}{r}\text { Blac } \\
\text { Birtlis }\end{array}$ & $\begin{array}{l}\text { Abs } \\
\text { Abrtions }\end{array}$ & $\begin{array}{r}\text { His } \\
\text { Births }\end{array}$ & $\begin{array}{l}\text { spanics } \\
\text { Abortions }\end{array}$ \\
\hline Prenatal care delaytmonths? & 4.98 & & 5.78 & & 5.80 & \\
\hline Schooling $<9$ & .00 & .04 & .06 & $.0 \epsilon$ & .15 & .08 \\
\hline Medicaid & .38 & .15 & .66 & .49 & .73 & .63 \\
\hline Self pay & .16 & .75 & .10 & .32 & .10 & .22 \\
\hline Poverty & 15.95 & 14,19 & 32.79 & 31.46 & 42.32 & 39.06 \\
\hline Total spontaneous abortions & .05 & & .04 & & .05 & \\
\hline Total induced abortions & .11 & .36 & .20 & .44 & .11 & .45 \\
\hline Late spontaneous abortions & .002 & 3.00 & .004 & 9.00 & .003 & 9.00 \\
\hline Age $<18$ & .20 & .37 & .41 & .48 & .38 & .11 \\
\hline Out of wedlock & .50 & 96 & .93 & .97 & .75 & $.0 \%$ \\
\hline Abortion providers & .46 & .55 & .53 & .51 & .55 & .55 \\
\hline Family pianning clinics & .82 & 84 & 1.54 & 1.42 & 1.79 & 1.60 \\
\hline l'arity & .36 & 11 & .21 & 1.36 & .27 & .45 \\
\hline WIC centers & .31 & .23 & .61 & .59 & .52 & .49 \\
\hline Prenatal care clinics & .55 & 60 & 1.06 & .98 & 1.01 & .98 \\
\hline Central/South Americans & & & & & .17 & .11 \\
\hline Mexican & & & & & .02 & .0 .1 \\
\hline Cuban & & & & & .008 & .02 \\
\hline other Hispanics & & & & & .04 & .05 \\
\hline Inverse Mill's ratio & .77 & .32 & .86 & .62 & .62 & .73 \\
\hline Observations & 1205 & 2007 & 5001 & 7236 & $448:$ & $37 \% 4$ \\
\hline
\end{tabular}

